\title{
Dealing with Intellectually Disabled Children
}

\section{S Islam ${ }^{1}, \mathbf{S}$ Islam $^{2}$}

\section{Introduction}

Intellectual disability (ID), also called intellectual development disorder (IDD) or general learning disability, ${ }_{1}$ and formerly known as mental retardation (MR $){ }^{2-4}$ is a generalized neurodevelopmental disorder characterized by significantly impaired intellectual and adaptive functioning.

The diagnostic term 'mental retardation' has already been eliminated. The American Psychiatric Association (APA)'s fifth revision of its Diagnostic and Statistical Manual for Mental Disorders (DSM-5) ${ }^{3}$ and the WHO in its next 11th edition of the International Classification of Diseases (ICD-11) will revise their terminology. ${ }^{4}$

Intellectual disability affects about $2-3 \%$ of the general population. $75-90 \%$ of the affected people have mild intellectual disability. Idiopathic cases accounts for $30-50 \%$ of cases. About a quarter of cases are caused by a genetic disorder. ${ }^{5}$ Cases of unknown cause affect about 95 million people as of $2013 .{ }^{6}$

Children with intellectual disability learn more slowly comparative to a normal child. Intellectually disabled (ID) children may take longer to learn language, develop social skills, and take care of their personal needs, such as dressing or eating. Learning will take them longer, require more repetition, and skills may need to be adapted to their learning levels. ${ }^{5}$ They may also exhibit some or all of the following characteristics: ${ }^{5}$

- Delays in oral language development

- Deficits in memory skills

- Difficulty learning social rules

- Difficulty with problem solving skills

Correspondence

Saad Islam

2nd year student

Dept. of Computer Science \& Engineering

North South University, Dhaka.

Email : saad.islam.9@gmail.com
- Delays in the development of adaptive behaviors such as self-help or self-care skills such as getting dressed, using the bathroom, and feeding oneself

- Lack of social inhibitors
To a parent, every child is special in his or her own way. They want their child to be physically and developmentally perfect. But children with ID have special needs that challenge parents to find ways to best prepare these children for the future and to handle any problem that may appear. For these the parents often face enormous strain on their psychological and economic resources.

\section{Family and Social behavior}

\section{Psychological stress}

When a child is diagnosed as ID, it becomes difficult for the parents to raise the child. ${ }^{7}$ It is not only hard for the children with ID to deal with difficult situations while growing up, but also their parents and family members. In this situation the role of parents are crucial to how the life of a ID child shapes up to be. To some family the birth of a child with ID at home is likely to be one of the most traumatic events. Some parents are able to cope up with such a difficult situation and some experience psychological stress. In fact, parents as well as the whole family experiences a variety of 'psychological stress' related to the child's disability. Parents and other children in the family must undergo a variety of changes to adapt to the presence of such a child.

Parents already have enough stress to deal with in today's world. Taking care of a child with special needs sometimes increases that stress. Parents of ID children undergo more than the average amount of psychological stress. There is no universal parental reaction to the added psychological stress of raising a retarded child. ${ }^{8}$

\section{Attitude}

Study showed that Rural and urban parents show attitude difference towards the child with retardation and their social adjustment also get affected. ${ }^{10}$ Society plays an important role in the upbringing of mentally retarded child. Some parents may feel ashamed of their children with 
retardation and consider them as a burden. Others may consider it as their duty to take care of such children. This may depend on background that can be a differentiating factor how the society views children with mental retardation. The subjects of lower and higher income did not show any significant difference in any of the variables. ${ }^{9}$

However, in 1994 Rao, conducted a study on 'Behaviour disorders in moderately mentally retarded children and the relation to parental attitude'.10 The sample comprised of parents of 60 moderately mentally retarded boys and girls. The findings of this study indicated that parents have a negative attitude towards their children with mental retardation. The most important implication of this study is the need for uplifting the parent's social and psychological well-being. It is expected that it will help the parents to deal effectively with their children having problem.

Most of the time, the attitude of society towards ID can become a burden too difficult to bear for parents of a special child. According to P. Roos 'our society fosters myths that lead to totally unrealistic expectations. As children we learn to anticipate success, achievement, wealth, love, and status. We expect wise parents, loving and lovable mates, and perfect children'.11 It is difficult to fathom what the real picture is in regards to society's behavior towards people with ID. Mental retardation is a formidable handicap in a complex society such as ours, which places great emphasis on intelligence and has little tolerance for deviation from cultural standards. ${ }^{11}$

\section{Adaptation}

Now a days globally,the response of the society to a child with ID is changing. During the last two decades, all over the world, there has been a movement away from institutional care and towards family based care of individuals with ID. ${ }^{12}$ In Bangladesh, an overwhelming majority of child with ID have traditionally been cared for in their families. Therefore, in this context the family has the key role. Many factors can influence the well-being of a family. One factor is certainly the emotional and physical health of the parents. ${ }^{9}$ They are the ones who deal with the issues associated with their child's disability and they are also required to maintain the household. Therefore, it is very important as parents, to take some time to care for oneself as individuals. When the parents' relationship is a strong and supportive one, it enriches family life for all members. Study showed that the presence of a child with special needs causes a crisis in the family. Most clinical observations shows that parents often are portrayed as exhibiting guilt, ambivalence, disappointment, frustration, anger, shame, and sorrow. ${ }^{13}$ The way parents adapt to this stress is determined to a degree by their mental state and intelligence. Their religious beliefs, attitude and support from friends and relatives also play an important role. Apart from support from friends and relatives, the support from one spouse to another is paramount. A vast research has indicated the high level of marital satisfaction support from husband(s) as expressed by mothers of retarded children is an important facilitator to the family having a child with mental retardation. The elements of such support include encouragement, assistance and feedback. ${ }^{14}$

In 1981 Friedrich and Friedrich studied the differences between parents of mentally retarded and normal children. ${ }^{15}$ The results indicated that parents of mentally retarded children reported less satisfactory marriages, less social support, lower physical well-being than parents of normal children.

\section{Coping with ID children}

Parents with ID children cannot have high expectations from their child, which they otherwise might have had with a normal child. According to P.Roos 'Our yearning for perfection is often channeled into our children, through whom we hope to realize our frustrated aspirations and our thwarted dreams of achievement and happiness. A retarded child is usually an unsuitable vehicle for fulfilling such parental hopes. ${ }^{12}$ If the parents have an only child who has ID, they need to come to terms with the fact that, they will always have a gap in that respect unfulfilled in their lives. They will need to cope with it by seeking other ways such as counselling to try and fill that gap.

Therefore, the new perspectives have resulted in a renewed wave of hope and optimism that, in turn, has been reflected in increased emphasis on the provision of individualized programs geared to meet the specific learning needs of ID clients. Hence, the goal of programming for ID persons might be defined as assisting the individual to reach and maintain his optimum level of functioning rather than his maximum level of functioning. ${ }^{12}$ It does not imply any denial of the retarded person's handicap. It involves rather exploring his hidden mental and physical capacities, so that his handicap becomes less pronounced. It means also that the retarded person has the same rights and obligations as other people, so far as this is possible. Nirje defined the essence of the concept as '.....making available to the mentally retarded patterns and conditions of everyday life which are as close as possible to the norms and patterns of the mainstream of society'. ${ }^{16}$

The growing acceptance of the normalization principle has given an increased emphasis upon individualization in programming for the ID. A key ingredient is the individual program plan, developed on the basis of a thorough interdisciplinary evaluation (by the Paediatritian and Child Psychiatrist) and consisting of: ${ }^{17}$

(1) a specific statement of long- and short-term goals, stated in behavioral terms that will yield measurable indices of progress; 
(2) the programmatic strategies that will be utilized to attain these goals;

(3) the persons responsible for carrying out the program and the training schedule to be followed; and

(4) a statement of the data that are to be collected in order to assess progress. ${ }^{17}$

It is encouraging to note that individual program plans must be accepted by the parents.

When the parents of a child with ID also have other normal children, they need to make sure to create an environment where both their children can grow up properly together. The requirements of everyday needs will vary from a child with ID and a normal child. Therefore the parents will have to make special considerations. They also have to face the fact that their normal child will have a childhood with hardship as well. Parents need to spare the time for their normal children to explain the situation of their special sibling. A lot of times, the parents themselves have to absorb the ridicule that society will throw to their ID child. But they need to handle the situation when their other children will also become the object of scorn from society for having a ID brother or sister.

There will also be a time, when the parents get old and cannot take care of their ID child. They will need to pass that responsibility to someone else. Often times, it will be their other children or family members or any institution. Therefore parents need to help create a strong bond between their child with ID and his/her siblings or relatives so they will not consider it as a burden to take care of him/her in the future.

\section{Conclusion}

Even though there may be exceptions, almost every one of us looks down on people with a disorder like this. Parents with ID children can get a much better quality of life with the right support, love from their friends and relatives, and respect from the society around them. This may not complete heal their wounds but it will at least make their journey of raising a special child easier.

\section{References}

1. Wilmshurst, Linda. general+learning+disability. Clinical and Educational Child Psychology an Ecological-Transactional Approach to Understanding Child Problems and Interventions. Hoboken: Wiley 2012:168. ISBN 9781118439982.

2. Tidy, Colin. General Learning Disability". Patient.info 25 January 2013.

3. "Rosa's Law" (PDF). Washington, D.C. : U.S. G.P.O. 2010. Retrieved 13 September 2013.

4. Ansberry, Clare.Erasing a Hurtful Label From the Books". New York: Wall Street Journal. 20 November 2010. Retrieved 4 December 2010

5. Daily DK, Ardinger HH, Holmes GE. Identification and evaluation of mental retardation "Am Fam Physician February 2000;61(4): 1059-67, 1070. PMID 10706158.
6. Global Burden of Disease Study 2013, Collaborators (5 June 2015). "Global, regional, and national incidence, prevalence, and years lived with disability for 301 acute and chronic diseases and injuries in 188 countries, 1990-2013: a systematic analysis for the Global Burden of Disease Study 2013.".Lancet (London, England). PMID 26063472

7. Peshwaria R, Ganguli. Families having person with mental retardation. Project Report, NIMH, Secunderabad 1995

8. Kumar V. Psychological Stress and Coping Strategies of the Parents of Mentally Challenged Children. Journal of the Indian Academy of Applied Psychology 2008;34 (2):227-31.

9. Ravindranadan V, Raju,S. Adjustment and Attitude of Parents of Children with Mental Retardation. Journal of the Indian Academy of Applied Psychology, January 2007; 33: (1) 137-141.

10. Rao. A study of Behaviour Disorders in Moderately mentally Retarded Children and their relation to Parental Attitude. Indian Journal of Clinical Psychology 1994; 21 : 27-31.

11. Roos P. Parents of Mentally Retarded People. Int. Journal of Mental Health.1977; (6)1:96 -119.

12. Shearer $A$. The integration of the Mentally Retarded individual in society. In: Prabhu, G,G. editor. Proceedings of the Third Asian Conference on Mental Retardation. Bangalore, India 1977;100-110.

13. Schild. Parental attitude towards children: A comparative study of parents of Normal children and parents of Mentally Retarded Children. Journal of Community Guidance and Research 1971; 9:117-122.

14. Houser, Seligman, Milton. A comparison of psychological stress and coping by Fathers of adolescents with mentally retarded and fathers of adolescents without mentally Retarded. Research in developmental Disabilities. Psychological Abstracts.1991;12: 251-260.

15. Friedrich W N, Friedrich W.L. Psychological aspects of handicapped children. American Journal of Mental Deficiency 1981; 85:551-56.

16. Nirje, Bengt. The Normalization Principle and Its Human Management Implications. In: Kugel R, Wolfensberger W, editor. Changing Patterns in Residential Services for the Mentally Retarded, 1969:Washington D.C

17. Roos P, Brian M M .Major Trends in Mental Retardation. Int J Ment Health $1977 ; 6(1): 3-20$. 